\title{
The COVID-19 Pandemic and the Greek 'Miracle'
}

\author{
Antigoni Fountouki, MSc, PhD ${ }^{1}$, Dimitrios Kosmidis, MSc, PhD² and Dimitrios Theofanidis, MSc, $P h D^{3^{*}}$ \\ ${ }^{1}$ Clinical Lecturer, Nursing Department, International Hellenic University, Thessaloniki, Greece \\ ${ }^{2}$ Staff Nurse, ICU, Kavala General Hospital, Greece \\ ${ }^{3}$ Assistant Professor, Nursing Department, International Hellenic University, Thessaloniki, Greece

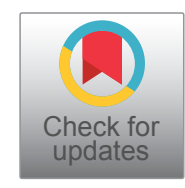

\begin{abstract}
Introduction: The current Coronavirus 2019-20 pandemic first appeared in Greece at the end of February 2020. The majority of the cases were related to travelers from Italy. Following the confirmation of the first three cases in Greece, on February $27^{\text {th }}$, all countrywide events were canceled. To date, (i.e. September 11, 2020) the total number of cases of the virus confirmed in the country is 12,734 and the number of deaths is 300 . Following the opening of the border to tourists at the end of June, the daily number of confirmed cases increased, mainly due to those being detected following tests at the country's entry points.
\end{abstract}

Aim: The purpose of this paper is to describe, analyze and discuss the relevant success in COVID-19 containment in Greece.

Results: Positive outcomes in Greece were due to the following actions and initiatives taken early on during this worldwide health crisis: The correct and swift identification of the first positive case alerted the National Board for Public Health; the virologist experts providing precise, clear and rigorous measures, which concerned the whole population and also the National Health System; postponing of planned medical and surgical procedures (elective surgeries); prohibition of hospital visiting; strict control of entry to health facilities; triage in hospital emergencies with the SARS-Covid-19 as a top priority; postponing of planned annual leave for health care personnel retention of doctors and nurses in the national health care system.

Conclusions: Despite the Greek stereotype of poor social compliance and strong-minded sense of independence, Greece deserves some acknowledgment for the responsibility of its citizens who have complied with the state's expert recommendations and acceptance of early lockdown despite some isolated incidents of disobedience. Overall, Greece has been globally widely perceived as a model paradigm during the first wave of the COVID-19 crisis.

\section{Keywords}

COVID-19, pandemic, Greece, Health care systems

\section{Introduction}

The COVID-19 pandemic in Greece is part of the worldwide pandemic of coronavirus disease 2019 (COVID-19) caused by severe acute respiratory syndrome coronavirus 2 (SARSCoV-2). The current Coronavirus 2019-20 pandemic first appeared in Greece at the end of February 2020. More specifically, the first patient diagnosed with SARS-Covid-19 coronavirus was a woman that returned to Greece on 26/2/2020 from Italy to Thessaloniki, Northern Greece.

Since then, the majority of the cases that followed the first recorded incident were related to travelers from Italy (which was severely affected by the virus), and a group of pilgrims who had visited Israel and Egypt as well as their family and social contacts. Under this light, the first officially recorder death from COVID-19 in Greece was a 66-year-old man, who died on March $12^{\text {th }}, 2020$ [1].

\section{Measures taken}

Following the confirmation of the first three cases in Greece, on February $27^{\text {th }}$, all countrywide carnival events, (due to commence from February $29^{\text {th }}$ and peak on March $1^{\text {st }}$ were canceled. Furthermore, by March $10^{\text {th }}, 2020$, there were 89 confirmed cases, mainly originating from the groups

*Corresponding author: Dimitrios Theofanidis, Assistant Professor, Nursing Department, International Hellenic University, lerosolimon 21, Kalamaria, 55134, Thessaloniki, Greece, Tell: $+30-6945227796$

Accepted: October 09, 2020

Published online: October 11, 2020

Citation: Fountouki A, Kosmidis D, Theofanidis D (2020) The COVID-19 Pandemic and the Greek 'Miracle'. J Nurs Pract 3(1):161-164

Copyright: (C) 2020 Fountouki A, et al. This is an open-access article distributed under the terms of the Creative Commons Attribution License, which permits unrestricted use, distribution, and reproduction in any medium, provided the original author and source are credited. 
mentioned above. Health and state authorities were swift in issuing recommendations and guidelines for the protection of the population, while the measures taken up to that date were local and included the partial closure of school units and the suspension of cultural and artistic events in the affected areas.

Yet, by March $10^{\text {th }}$, due to the ongoing viral outbreak in various 'pockets' of the country in combination with a relative failure by the public to adhere to the proposed restriction measures, the government decided to close all educational venues (at all levels), followed by the national mandatory closure on March $13^{\text {th }}$, of cafes, bars, museums, shopping centers, sports facilities and restaurants. Moreover, by March $16^{\text {th }}$, all remaining shops (except food outlets) were closed, and all religious functions (of all denominations) were suspended, including the customarily highly attended Easter ceremonies of the Greek Orthodox faith.

Bakeries, supermarkets, take-away outlets, pharmacies, private health services and some other businesses such as small food outlets serving local neighborhoods remained open. As the pandemic progressed, a new initiative was introduced by the Ministry of Health on March $16^{\text {th }}$, i.e. daily routine television updates on the development of the pandemic in Greece and the government's emergency decisions to address it. These were extremely popular and well-received by the general population due to the charisma and sincerity of the virology team. These early evening information sessions were continued until the end of May 2020 but were again reinstated in mid-July 2020 [2].

Since March $23^{\text {rd }}$, significant restrictions were imposed on the movement of citizens throughout the territory, i.e. all non-essential motilities were forbidden with certain exceptions in place (health reasons mainly or travel to essential work). Therefore, a special form was to be filled-in whenever leaving the home, announcing and verifying on paper or mobile: i) Moving to or from one's workplace during work hours, ii) Going to the pharmacy or visiting a doctor, iii) Going to a food store, iv) Going to the bank for services not possible online, v) Assisting a person in need of help, vi) Going to a major ritual (funeral, marriage, baptism) or movement, for divorced parents, which is essential for contact with their children, and vii) Moving outdoors for exercising or taking one's pet out, individually or in pairs.

These were the exclusive reasons for 'breaking' home lockdown and were strictly reinforced by police although the general consensus is that these measures were well accepted by the public mainly due to the convincing messages conveyed by the state virologists.

It was later decided to extend the restrictions until April $27^{\text {th }}$, but on April $23^{\text {rd }}$ a further extension was announced until May $4^{\text {th }}$. Although it seemed that the restrictions were likely to be continued into the summer, the government phased out emergency measures on May $4^{\text {th }}$, lifting travel restrictions and restarting daily operations, mainly due to demands from the tourism industry which is known to be one of the country's main assets and economic drivers. Thus, as from May $4^{\text {th }}$, after a 42-day lockdown, Greece began to lift gradually restrictions on movement and to restart business activities as usual.

To date, (i.e. September $19^{\text {th }}, 2020$ ) the total number of cases of the virus confirmed in the country is 14,738 and the number of deaths is 327 with 3,804 recoveries [3]. Following the opening of the border to tourists at the end of June, the daily number of confirmed cases increased, mainly due to those being detected following tests at the country's entry points. In addition, a total of 4,873 recoveries were announced by August $31^{\text {st }}$.

\section{The Greek 'success story'}

Although in China and other parts of the world, the epidemic had reached uncontrollable proportions, the Greek health ministry had alerted the National Health System and its employees to prepare and expect for increasing cases. Thus, the relevant success in virus containment for Greece as presented by hard global statistics may be due to the following actions and initiatives taken early on during this worldwide health crisis:

- The correct and swift identification of the first positive case alerted the National Board for Public Health (NBPH).

- The virologist experts providing precise, clear and rigorous measures, which concerned the whole population and also the National Health System (NHS). These included daily 18:00 hour briefings via national TV, delegated to virologists communicating public messages to explain and contain the pandemic.

- Postponing of planned medical and surgical procedures (elective surgeries).

- Prohibition of hospital visiting.

- Strict control of entry to health facilities.

- Triage in hospital emergencies with the SARS-Covid-19 as a top priority.

- Postponing of planned annual leave for health care personnel.

- Retention of doctors and nurses in the national health care system.

During this health and societal crisis, the health community as a whole, i.e. nurses, doctors, paramedics, administrators, safety and cleanliness personnel, have demonstrated and are continuing to demonstrate a unique consensus in the effective management of the pandemic. Yet, as most of the responsibility for crisis management in the hospitals lies with the nursing staff, their routine clinical role is enhanced with implementing effective action plans in cooperation with the Hospital Infections Committees and the Administrations. Hence, despite being chronically understaffed, public health hospitals remained functional with nurses at the forefront of patient care [4].

\section{Private initiatives}

In gratitude to 4,600 nurses and nurse assistants, physicians and cleaners working on the front line at Intensive Care 
Units (ICUs) and the hospital reference hospitals for COVID-19 in Greece the Stavros Niarhos Foundation provided a generous grant which totaled $6.9 \mathrm{~m}$ Euros. Thus, the charity organization founded by a Greek shipping magnate recognized the self-sacrificial work of the public health care personnel during the pandemic period and in recognition of their offer, the foundation offered an honorary contribution to all of them.

In view of the expected second wave of COVID-19 pandemic, the foundation is preparing for another supportive donation of $16.5 \mathrm{~m}$ Euros. The aim is to renovate premises in 15 hospitals, and in particular, to add a total of 155 intensive care beds and 19 increased care beds, as well as to carry out training programs for ICU staff.

This exceptional private initiative was well received by health care staff as this was the first time that they had all been rewarded on a massive scale for the "real, everyday heroes who put their lives at risk, to save the lives of others". This honorary support, which was given to everyone equally, was a practical thank-you from the foundation. Yet, the wider society by extension has also been acknowledging the dedication and commitment of Greek nurses and doctors during this potentially devastating health crisis.

\section{Nurses' voice}

Early nursing accounts of the pandemic as displayed in the media portray the crisis from a real life clinical perspective. Within certain extracts it can be seen that regular surveillance of the disease within the hospital was a key part of the overall effort made. Moreover, it was necessary to establish patient and suspected disease reception centers, where specific procedures were applied on the basis of strict clinical guidelines. Continuing training of personnel in the use of personal protective equipment and in compliance with procedures was also part of their routine, especially within the context of limited resources.

On a daily basis, nurses, have to record and monitor suspected and positive cases in the hospital, manage samples and results, provide information to patients, staff and, in some cases, their close contacts. This is in addition, to the daily updating of hospital staff, and coping with extra concern and stress of contracting the virus themselves and therefore transmitting it to their loved ones.

By definition, the nursing workload is entrusted with additional tasks and processes required by the condition of the patients in the ICU. Beyond Covid-19 cases, there are post-surgical patients, polyvalent patients, patients with very severe respiratory or renal insufficiency, and patients with critical multi-pathologies. Nurses are therefore called upon to deal with an unprecedented disease with an essentially unknown epidemiological identity $[5,6]$. The current uncertainty coupled with the tens of thousands of victims in neighboring countries and throughout the world, plus the tremendous difficulties in working conditions created by constant need for Personal Protection Equipment requires enormous effort on both a physical and psychological preparedness in order to serve our patients [7].

In this light, the current pandemic served not only as a 'test' for the capabilities of the Greek Health System but also as a challenge, i.e. to find the extent to which both staff and services may exceed their own boundaries. Thus, throughout the pandemic, the nursing staff has remained vigilant, and physically available on a routine basis. Yet, there was no room for expressing fatigue or burn-out in a health care system already understaffed and overwhelmed.

\section{Covid-19 and migrants}

Currently in Greece (mid September 2020) the quarantine for Covid-19 has been lifted, social life has returned to cautious normality, yet measures for public health and safety are still in place with the use of a facial mask being obligatory on public transport, shops, public buildings with special restrictions applying for social gatherings.

Yet, despite the country's relative success in controlling the virus there has been mounting anxiety over the risk of contagion within its migrant and refugee population largely placed in camps. The Greek island of Lesbos has been hosting about 12,000 migrants and refugees over the past few years at the now infamous 'Moria' camp. A few weeks ago, about 30 cases of COVID-19 were detected amongst the camp's population which was subsequently destroyed by fire. Although the COVID-19 cases were instructed to isolate, during the blaze, they found the chance to mingle with the rest of the migrants and refugees in a futile attempt to avoid isolation as in their eyes this was associated with stigma and could impede their efforts for future transfer to northern Europe [8]. Although a new camp (i.e. Kara Tepe) is now being completed, only a handful of the original 30 COVID-19 cases were willing to be transferred there and stay in isolation, while only 2,000 of the total migrants and refugees population were moved there [9]. Again, amongst these, more new COVID-19 cases were detected. Thus, medical tents are now being set up, and two quarantine zones as well, for the several dozen people who have tested positive for COVID-19.

Yet, even for the migrants and refugees who are on mainland Greece, the situation with regards to COVID-19 is difficult. Although all asylum applications were suspended in March 2020, these are now gradually being lifted and interviews and appeal submissions are being considered [10]. There was a brief temporary extension for those with applicants' cards and residence permits that were due during the initial lockdown period and these remained valid [11]. Although currently, migrants and refugees can apply for services online, the majority still prefers to wait in long queues outside the immigration offices with the appropriate social distancing measures not being reinforced due to the overwhelming number of applicants, a relevant inability to reinforce law and order (by Greek authorities) coupled with an eager effort to be 'the first in line' (by the migrants and refugees).

\section{Conclusions}

In general, the measures put in place in Greece, described in detail in this paper, were among the most proactive and strictest in the world. Yet, despite the Greek stereotype of poor social compliance and strong-minded sense of independence, these measures were widely accepted by the popu- 
lation. Thus, they were praised and credited internationally for having slowed the spread of the pandemic and therefore keeping the number of deaths proportionally among the world's lowest.

In this light, Greece deserves some acknowledgment for the responsibility of its citizens who have complied with the state's expert recommendations and acceptance of early lockdown despite some isolated incidents of disobedience. Overall, Greece has been globally widely perceived as a model paradigm during the first wave of the Covid-19 crisis.

\section{References}

1. (2020) Greek Ministry of Health.

2. (2020) EODY - National Public Health Organization.

3. (2020) World meters.
4. (2020) Visit Greece.

5. Fountouki A, Pediaditaki O, Theofanidis D (2011) Nursing staff under heavy stress: Focus on Greece A critical review. International Journal of Caring Sciences 4: 11-20.

6. Theofanidis D (2015) Sick by appointment? Health Science Journal 9: 1-3.

7. Theofanidis D (2017) Greek nursing under austerity. International Journal of Caring Sciences 10: 601-606.

8. (2020) (IOM) The International Organization for Migration.

9. (2020) UNHCR. The UN refugee agency.

10. Garcia Al, Theofanidis D, Fountouki A (2020) Impact of migration in Europe: A new challenges for health care in spain and Greece.

11. Theofanidis D, Fountouki A (2019) Refugees and migrants in Greece: An ethnographic reflective case study. Journal of Transcultural Nursing 30: 26-31.

DOI: $10.36959 / 545 / 378$ 